\title{
-Original-
}

\section{Sex-related effects of sleep deprivation on depressive- and anxiety-like behaviors in mice}

\author{
Rocio E. GONZALEZ-CASTAÑEDA ${ }^{1,2)}$, Alma Y. GALVEZ-CONTRERAS ${ }^{1)}$, \\ Carlos J. MARTÍNEZ-QUEZADA ${ }^{1)}$, Fernando JAUREGUI-HUERTA ${ }^{1)}$, Joaquin GRCIA- \\ ESTRADA $^{1)}$, Rodrigo RAMOS-ZUÑ̃IGA ${ }^{1)}$, Sonia LUQUIN ${ }^{1)}$, and Oscar GONZALEZ-PEREZ ${ }^{3)}$ \\ 1) Laboratorio de Microscopia de Alta Resolución, Departamento de Neurociencias, Centro Universitario de \\ Ciencias de la Salud, Universidad de Guadalajara. Jalisco, 44340, Mexico \\ 2) Instituto Tecnológico y de Estudios Superiores. Guadalajara, Jalisco, Mexico \\ 3) Laboratorio de Neurociencias, Facultad de Psicología, Universidad de Colima, Colima, 28040, Mexico
}

\begin{abstract}
Anxiety and depressive symptoms are generated after paradoxical sleep deprivation (PSD). However, it is not clear whether PSD produces differential effects between females and males. The aim of this study was to assess the effect of PSD on anxiety- and depressive-like behaviors between sexes. Male and female BALB/c mice were divided in three groups: the control group, the 48-h PSD group and the 96-h PSD group. Immediately after PSD protocols, the forced swimming and open field test were applied. Sucrose consumption test was used to evaluate the middle-term effect of PSD. We found that corticosterone serum levels showed significant differences in the 96-h PSD females as compared to 96-h PSD males. In the open-field test, the 48-h and 96-h PSD females spent more time at the periphery of the field, and showed high locomotion as compared to males. In the elevated plus maze, the 48-h PSD females spent more time in closed arms than males, which is compatible with anxiety-like behavior. The forced swim test indicated that the 96-h PSD males spent more time swimming as compared to the 96-h PSD females. Remarkably, the 96-h PSD males had lower sucrose intake than the 96-h PSD females, which suggest that male mice have proclivity to develop a persistent depressive-like behavior late after PSD. In conclusion, male mice showed a significant trend to depressive-like behaviors late after sleep deprivation. Conversely, female have a strong tendency to display anxiety- and depressive-like behaviors immediately after sleep deprivation.

Key words: anxiety, depression, female, male, sex-dependent effect, sleep disorder
\end{abstract}

\section{Introduction}

Sleep deprivation can be produced by physical or psychological factors. In both cases, consequences on organic homeostasis involve disruptions in circadian rhythm, mental impairments, hormonal changes and other medical problems [16]. Regardless the etiology of dreaming disruption, sleep is a physiological need that must be satisfied to preserve life $[4,57]$. Sleep help preserve the homeostasis of spatial learning $[3,58]$, mem- ory consolidation $[17,34]$ and restoration of neural tissue [4]. Consequently, substantial changes in the sleep pattern are considered neurological disorders, which may generate systemic alterations in humans [33], such as: coronary diseases, stress and activation of pro-inflammatory cytokines [19, 25, 44, 52]. Some studies indicate that sleep deprivation can trigger depressive-type behaviors [2]. In contrast, other reports indicate that sleepdeprived subjects show an antidepressant effect, but this episode may be transient or can even deteriorate the

(Received 1 June 2015 / Accepted 23 September 2015 / Published online in J-STAGE 6 November 2015)

Address corresponding: R.E. Gonzalez Castañeda, Neuroscience Department, Universidad de Guadalajara, Sierra Mojada No. 950, Guadalajara, Jal. 44340, Mexico

(C)2016 Japanese Association for Laboratory Animal Science 

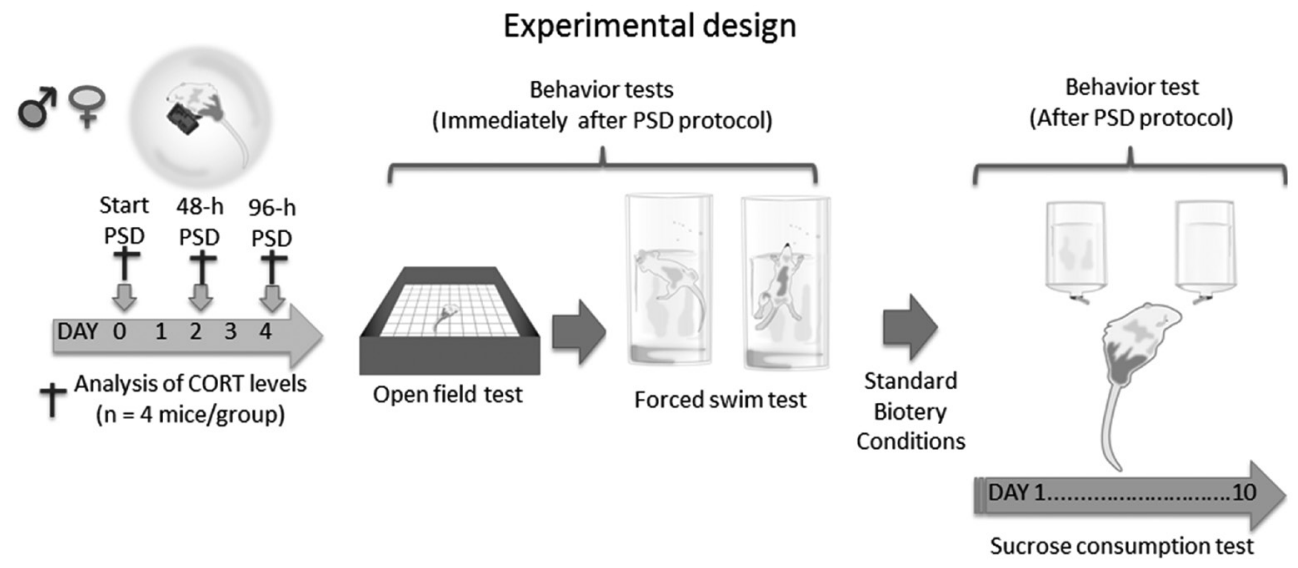

Fig. 1. Experimental design and time course of sleep deprivation and behavioral assays.

clinical course of depression [23,47]. Yet, the neural mechanism of this paradoxical finding is not well understood.

In humans, recent evidence indicates that males and females display different electroencephalographic patterns during the sleep period $[5,13,38]$. Women have better continuity and efficiency of the sleep period than men [38]. The administration of exogenous female and male sex hormones modulates sleep process [27]. Interestingly, insomnia, anxiety, depression, and other psychiatric disorders are more frequent in women [38]. Despite these behavioral differences, most of the experimental studies about paradoxical sleep deprivation (PSD) and depressive- or anxiety-like behaviors are performed in male mice. Female mice have rarely been included in PSD research. Thus, the current understanding of the influence of sex in the development of anxietyand depression-like behaviors in PSD remains unclear. The aim of the present study was to examine the possible gender difference in depressive- and anxiety-like behaviors at different time points of PSD. Our findings indicate that sleep deprivation affects males and females differently in the induction of anxiety- and depression-like behaviors.

\section{Experimental Procedure}

Sixty-day-old BALB/c mice were obtained from the animal research facility of the Biomedical Research Center of Guadalajara Mexico. All animals were housed in standard polycarbonate cages, under constant temperature $\left(22 \pm 2^{\circ} \mathrm{C}\right)$ and were maintained in 12-h light- dark cycle with free access to food and tap water. Only female mice with synchronized estrous cycle, determined by vaginal cytology, were included in the study. All experimental procedures were performed in accordance to the guidelines of the Committee on Animal Care and Research of the University of Guadalajara, Mexico and special efforts were made to minimize the number of animals used in this study.

\section{Paradoxical sleep deprivation (PSD) procedure}

The animals were randomly divided in six groups $(\mathrm{n}=12$ animals per group): the control group (males and females), the 48-h PSD (males and females) and the 96-h PSD (males and females) (Fig. 1). To produce PSD, the animals were exposed to a multiple-platform device interconnected by wood bridges, which allowed mice to walk freely throughout the device $[11,51]$. Briefly, the mice were placed on $3.5-\mathrm{cm}$-diameter platforms ( 25 total) located in a water tank $(1.80 \mathrm{~m}$ width and $0.50 \mathrm{~m}$ height $)$. All the platforms were placed $1 \mathrm{~cm}$ above the water surface. Thus, when the animals reached the paradoxical phase of sleep, they presented muscle atonia and fell into the water and woke up. Food and water were provided ad libitum by individual feeders located on each platform. Throughout this study, the experimental room was kept under light-dark cycle (lights on at 07:00 $\mathrm{h}$ and off at 19:00 h) and the water in the tank was also under controlled temperature $\left(26 \pm 1{ }^{\circ} \mathrm{C}\right)$. The control group was maintained under similar housing conditions as those of the PSD groups. To evaluate the immediate effects of sleep deprivation in all groups, we quantified the corticosterone blood levels, anxiety-like behavior and 
depressive-like behaviors immediately after PSD. To analyze the long-lasting effects of PSD, we used the sucrose preference test one day after PSD and for ten consecutive days.

\section{Corticosterone assay}

Animals were decapitated ( $\mathrm{n}=4$ animals per sex group) at $0-\mathrm{h}, 48-\mathrm{h}$ and $96-\mathrm{h}$ of sleep deprivation. All animals were gently handled to minimize stress and samples were obtained immediately after sleep deprivation at 8:00 P.M. Blood samples were collected into polyethylene tubes containing EDTA anti-coagulant and were centrifuged at room temperature for $10 \mathrm{~min}$ at 5,000 rpm. The plasma fraction was isolated and stored at $-20^{\circ} \mathrm{C}$ until processing. Samples were analyzed by a researcher 'blinded' to group assignment and processed by ELISA following the kit instructions for Corticosterone Enzyme Immunoassay (Oxford Biomedical Research).

\section{Behavioral analyses}

We selected the BALB/c strain because it consistently exhibits higher levels of emotional reactivity in the open field than other mouse strains [12]. To analyze the immediate effects of PSD between sexes on anxietyand depressive-like behaviors, we used the open field test [35] and the forced swim test [36] [8, 9, 41]. To determine the persistent effects of PSD on behavior, we used the consumption of sucrose test (SC) [40]. Since rodents are nocturnal animals and most of their activity occurs at night [26] we performed all the behavioral assays after 19:00 h, as described below.

\section{Open field test [35]}

The OF is a behavioral test commonly used to assess spontaneous motor and motivational responses associated with the natural fear of rodents for exploring open and novel environments [21]. Thus, rodents need to counterbalance between their natural interest for exploring and their fear for uncovered areas [7]. The procedure was performed in a temperature-, noise- and light-controlled room. The locomotor activity on an acrylic cage $(60-\mathrm{cm}$ width $\times 60$-cm length $\times 20$-cm height) was recorded using a ceiling-mounted camera. Mice $(n=8$ per sex and PSD groups) were placed at the center of the open field and were left to ambulate freely for $5 \mathrm{~min}$. This period of time help minimize the physical effort that animals may be suffering after sleep deprivation. We analyzed grooming, rearing, locomotor activity and time spent in the center area. The peripheral area was a $15-\mathrm{cm}$ wide zone bordering the outer sidewall of the device, whereas the inner area was the remainder of the central zone (45 $\times 45 \mathrm{~cm}$ ). The interpretation of data specifies that a reduced frequency of grooming/rearing and motor activity indicate a higher anxiety level $[7,10,22]$. After each test, the open field was cleaned with $70 \%$ ethanol before a new animal was tested. An evaluator blinded to group assignments quantified all data.

\section{Elevated plus-maze test}

The plus maze apparatus consisted of two open arms (50 cm length $\times 10 \mathrm{~cm}$ width) and two closed arms (50 cm length $\times 10 \mathrm{~cm}$ width), which have opaque walls (25 cm height) with an open roof [21]. The arms were arranged so as to the open arms were opposite to each other and all the four arms were opposite to each other. All the four arms were connected together with a central square of $10 \mathrm{~cm} \times 10 \mathrm{~cm}$. The maze was elevated at $60 \mathrm{~cm}$ height. Immediately after PSD, all animals were placed in the center of the maze facing towards one of the closed arms and allowed to freely walk for $5 \mathrm{~min}$. We quantified the time spent in open and closed arms as well as the time spent at the center of device. All assays were video recorded and analyzed by an observer blinded to group assignments.

\section{Forced swimming test}

FS is a widely accepted model for assessing depressive-like behavior $[29,41]$. We used this test to evaluate the depressive-like behavior immediately after PSD in animals that were not previously exposed to another behavioral test. Briefly, we used a transparent container (30-cm height $\times 20$-cm diameter) filled with water (at $27 \pm 1^{\circ} \mathrm{C}$ ) to reach a $15-\mathrm{cm}$ depth. Animals $(\mathrm{n}=8$ per sex group and $\mathrm{PSD} /$ control group) were then individually placed into the cylinder for $5 \mathrm{~min}$. The water in the container was changed for each assay. We registered the swimming behavior as defined by the movement around the surface of water and throughout the swimming chamber. In this test, a reduced swimming behavior suggested depressive-like behavior [29, 41]. Every behavioral session was video recorded and analyzed by a 'blinded' observer to group assignments.

\section{Sucrose consumption (SC)}

To evaluate persistent depression-type behavior induced by PSD, we quantified the SC for ten days, as 
described previously [29]. For this purpose, we used animals that were not previously exposed to other behavioral tests. Thus, PSD and non-PSD mice $(n=8$ per sex group) were placed for 10 days in housing cages with two 50-ml drinking tubes: one of them containing distilled water and another one containing distilled water plus $1 \%$ sucrose $(1 \% \mathrm{w} / \mathrm{v})$. This sucrose concentration was used to minimize the osmotic effect of glucose [6]. To determine sucrose consumption the total drinking volume of liquid (including distilled water and sucrose ingestion) was quantified and the percentage of sucrose intake was then calculated [40]. Thus, animals with depressive-like behavior (anhedonia) show a reduction in $\mathrm{SC}$ rates [40]. To avoid habituation, the position of bottles was changed during the task.

\section{Statistical analysis}

All results were expressed as the mean \pm S.E.M. Nonparametrical analysis was selected after the kurtosis evaluation. Thus, statistical analysis was performed with the Kruskal-Wallis ANOVA test followed by the MannWhitney "U" test with Bonferroni correction to determine significant differences between groups. The level of confidence was set at $95 \%(P<0.05)$

\section{Results}

Analysis of corticosterone levels in males and females

To determine the effects of PSD in corticosterone blood levels per animal sex, we quantified the corticosterone levels at different time points in all groups (Fig. 1). In the control groups (time point " 0 "), we did not find statistically significant differences $(\mathrm{U}=2 ; P=0.157)$ between males $(60.50 \pm 7.3 \mathrm{ng} / \mathrm{ml})$ and females $(41.07 \pm$ $4.4 \mathrm{ng} / \mathrm{ml}$ ) (Fig. 2). At 48-h PSD, females showed slightly higher levels of corticosterone $(245.32 \pm 63.5 \mathrm{ng} / \mathrm{ml})$ as compared to males $(159.30 \pm 46.5 \mathrm{ng} / \mathrm{ml})$, but no statistically significant differences $(\mathrm{U}=2 ; P=0.157)$ were obtained between sexes in these groups. However, at 96-h PSD, females showed a 3-fold increase (238.05 \pm $19.2 \mathrm{ng} / \mathrm{ml}$ ) in corticosterone levels as compared to males ( $75.20 \pm 37.05 \mathrm{ng} / \mathrm{ml} ; \mathrm{U}=0 ; P=0.034)$. These findings suggest that $96-\mathrm{h}$ PSD produces a persistent increase in the corticosterone levels in females. Throughout this study, we quantified the food consumption and the weight gain of all animals. Our data showed no statistically significant differences in these variables. Thus, corticosterone changes could not be attributed to this

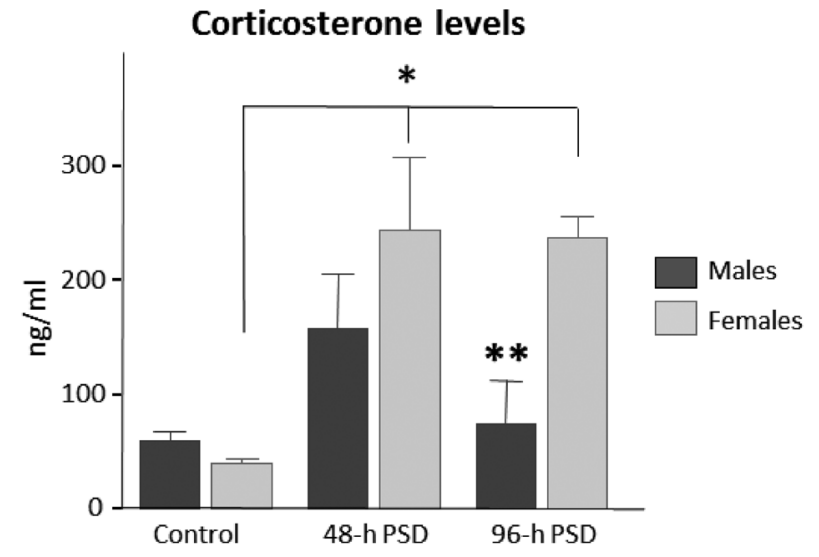

Fig. 2. Corticosterone serum levels between females and males after paradoxical sleep deprivation. In male animals, corticosterone levels showed a transient increase, whereas in females showed a persistent increase in hormone levels throughout the study. Bars indicate mean \pm SEM. $* P<0.05$ among females; $* * P<0.05$ between $96-\mathrm{h}$ PSD males vs. 96-h PSD females. Statistical test: KruskalWallis ANOVA.

type of physiological changes.

PSD-induced anxiety-like behavior in males and females

To assess anxiety-like behavior associated with PSD, we analyzed the spontaneous locomotion and motivational responses on the open-field maze and the elevated plus maze. Ten min after PSD, we studied grooming activity, locomotor performance, rearing and time spent in the inner (center) area of the field. We found that male and female controls showed lesser grooming activity than the PSD animals (Fig. 3A). In the 48-h PSD groups, male mice $(1.61 \pm 0.43)$ groomed more frequently than females $(0.06 \pm 0.03 ; \mathrm{U}=15, P=0.022)$. No statistically significant differences were found at 96-h PSD between males $(1.06 \pm 0.31)$ and females $(0.43 \pm 0.31)$. The analysis of locomotor activity (Fig. 3B) showed that the 48-h PSD males $(296.25 \pm 118 \mathrm{~cm})$ covered shorter distances than the 48-h PSD females $(663 \pm 107 \mathrm{~cm}$; U=18; $P=0.05)$. After 96-h PSD, we did not find statistically significant differences between male $(394.37 \pm 166 \mathrm{~cm})$ and female mice $(513.5 \pm 101 \mathrm{~cm} ; \mathrm{U}=32, P=0.47)$. No significant differences were found between the control groups (non-sleeping deprived animals): males vs. females. The analysis of rearing behavior did not show statistically significant differences among groups (data not shown). Finally, we then evaluated the time spent in the outer (periphery) area of the open-field maze 

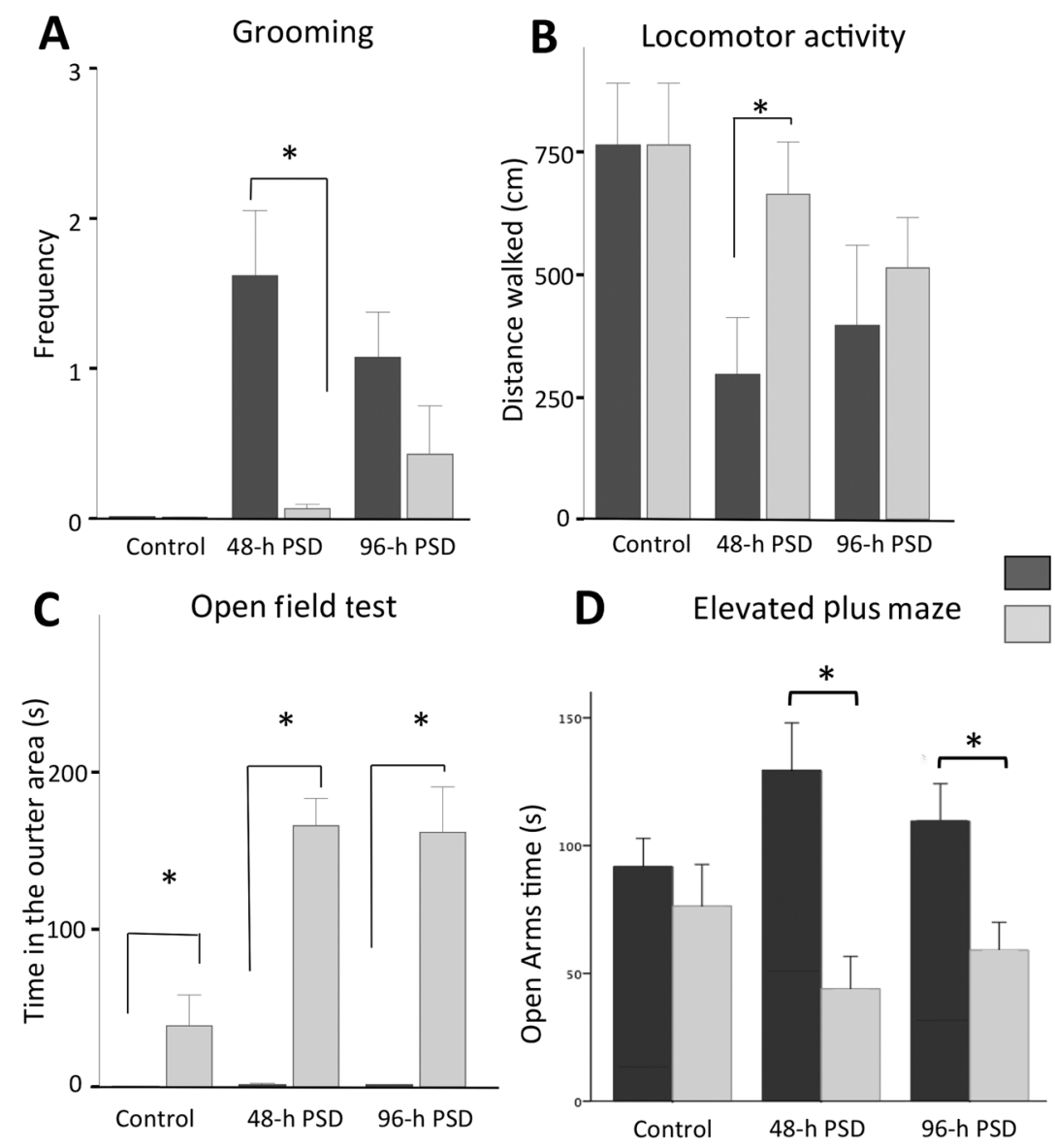

Fig. 3. Anxiety assessment with the open field test and elevated plus maze. In the open field test, the plots show the comparison between female and male mice in grooming behavior (A), locomotor activity (B) and time spent in the outer area (C). The time spent in the open arms of the open field (D) revealed that females spent statistically significant less times as compared to male mice. PSD: Paradoxical Sleep deprivation. Bars indicate the mean $\pm \mathrm{SEM}$. * $P<0.001$, Mann-Whitney "U” test.

(Fig. 3C). Throughout the study, female mice spent more time in the outer area as compared to male mice. Interestingly, sleep deprivation increased this behavior in the female groups. Thus, female mice spent more time at the periphery of field as compared to males at 48-h PSD (female $165.6 \pm 18 \mathrm{~s}$ vs. males $1.76 \pm 0.63 \mathrm{~s}$; $\mathrm{U}=0$, $P=0.001$ ) and at 96-h PSD (females $162.4 \pm 29 \mathrm{~s}$ vs. males $1.41 \pm 0.55 \mathrm{~s}$; $\mathrm{U}=0, P=0.001$ ).

To confirm whether the PSD induced anxiety-like behavior, we exposed the animals to the elevated plus maze (Fig. 3D). Our results showed that the 48-h PSD (44 $\pm 13 \mathrm{~s})$ and the 96-h PSD $(59 \pm 11 \mathrm{~s})$ females spent less time at the open arms as compared to the 48-h PSD $(129 \pm 18 \mathrm{~s} ; \mathrm{U}=3,000 ; P=0.004)$ and the 96-h PSD males $(109 \pm 15 \mathrm{~s} ; \mathrm{U}=6,000 ; P=0.02)$. The reciprocal quantifi- cation as assessed by the time spent in the closed arms corroborated these observations. Both the 48-h PSD and the 96-h PSD females spent statistically significant more time than males in the closed arms (data not shown). Taken together, the results of open field and plus maze data suggest that sleep-deprived females showed more anxiety-like behaviors than PSD males.

\section{Short-term effects of PSD in depressive-type behavior}

To analyze the depressive-like behavior immediately after PSD, we applied the forced swimming test in animals that were not previously exposed to another behavioral assay. At 96-h PSD, we found statistically significant differences in the time of immobility between males $(28 \pm 5 \mathrm{~s})$ and females $(85 \pm 16 \mathrm{~s} ; \mathrm{U}=10.5, P=0.014)$ 


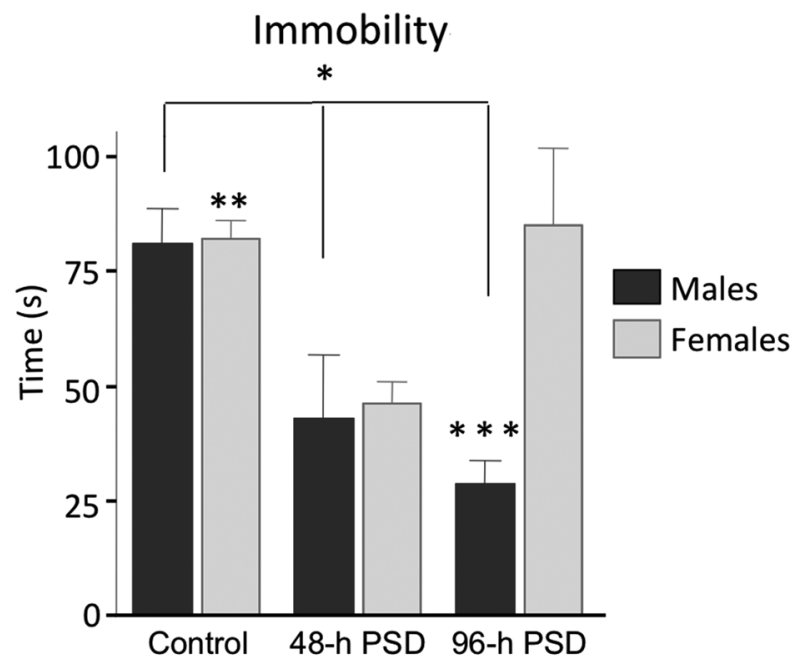

Fig. 4. Short-term effects of PSD in depressive-type behavior. Immobility time in the forced swim test applied immediately after PSD. Male mice showed lees depressive-type behavior as exposed to PSD. Statistically significant differences between males and females were only found at 96-h PSD. Bars indicate mean \pm SEM. PSD: Paradoxical Sleep deprivation. $* P<0.05$ among male groups; $* * P<0.05$ between control and 48-h PSD females; $* * * P<0.05$ between the 96-h PSD male group vs. the 96-h PSD female group. Statistical test: Kruskal-Wallis ANOVA.

(Fig. 4). No statistically significant differences were found between the 48-h PSD groups (females $46 \pm 5 \mathrm{~s}$ vs. males $42.8 \pm 13.9 \mathrm{~s} ; \mathrm{U}=29, P=0.83)$. In the control animals, the statistical analysis between females $(82.28$ $\pm 9 \mathrm{~s})$ and males $(81 \pm 8 \mathrm{~s} ; \mathrm{U}=26, P=0.87)$ did not show significant differences. Interestingly, the 48-h and 96-h PSD males showed a significant decrease in the time of immobility as compared with the male control group (Fig. 4). In contrast, the female mice only showed a decrease in the immobility time at the 48-h PSD group (Fig. 4). Taken together, the progressive reduction in the immobility time in male mice suggests that they are more resilient than females to develop depressive-like behaviors after PSD.

\section{Long-term effects of PSD in depressive-type behavior}

To determine long-term effects of PSD on depressivelike behavior, we returned the animals to their cages and sucrose intake was then quantified for 10 days after the sleep deprivation period. Our data indicates that sucrose consumption was significantly modified by PSD in both males and females (Fig. 5). The 96-PSD groups showed statistically significant differences between females 57

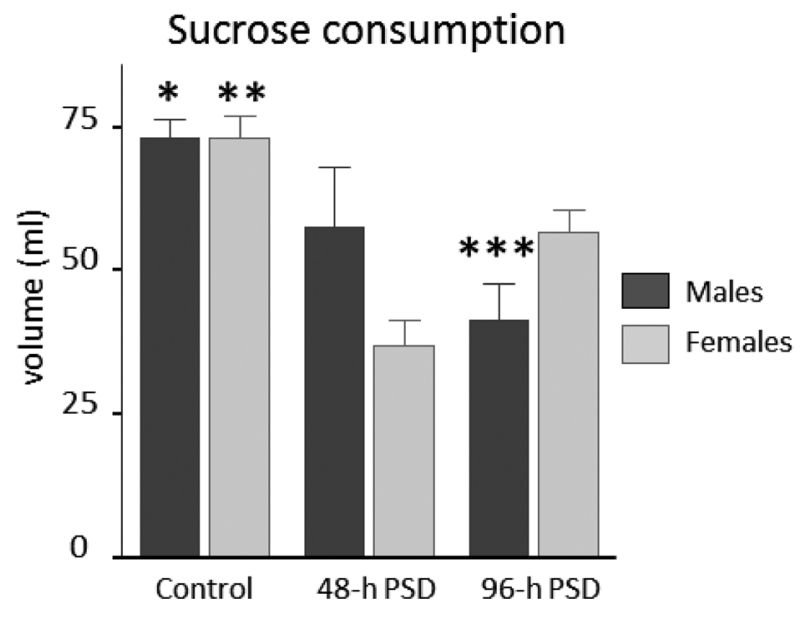

Fig. 5. Long-term effects of PSD in depressive-type behavior. Sucrose consumption analysis was done for ten days after the PSD protocols in both sexes. Bars indicate mean \pm SEM. PSD: Paradoxical Sleep deprivation. $* P<0.05$ between controls and 48-h PSD males; $* * P<0.05$ among female groups; $* * * P<0.05$ between the 96 -h PSD male group vs. the 96-h PSD female group. Statistical test: Kruskal-Wallis ANOVA.

$\pm 4 \mathrm{ml}$ as compared to males $41 \pm 6 \mathrm{ml}(\mathrm{U}=15 ; P=0.034)$. Interestingly, The 48-h PSD did not modify the sucrose consumption between females ( $37 \pm 4 \mathrm{ml})$ and males (58 $\pm 10 \mathrm{ml} ; \mathrm{U}=2, P=0.157)$. The control animals did not show statistically significant differences in this parameter: female mice $73 \pm 5 \mathrm{ml}$ vs. male mice $73 \pm 3 \mathrm{ml}$ $(\mathrm{U}=2, P=0.16)$. Taken together (Table 1), these findings indicate that PSD induces a sustained anhedonic behavior in both sexes, but male mice appear to be more susceptible to display this depressive-like behavior.

\section{Discussion}

The present study describes the effect of sleep deprivation at different time points and compares behavioral differences between males and females. Particular care was taken to use female mice with synchronized estrus cycle, which may reduce the variation of sex hormones during the study. Our data suggest that PSD generates differential anxiety- and depressive-like behaviors depending on individual sex. PSD was performed by the method of multiple platforms, which is one of the most used protocols for inducing deprivation of paradoxical sleep and non-REM sleep [22, 31, 32]. The inclusion of several platforms promotes the social interaction among the experimental subjects, which appears to reduce the 
Table 1. Summary of data

\begin{tabular}{|c|c|c|c|c|c|c|}
\hline \multirow{2}{*}{ Test } & \multicolumn{3}{|c|}{ Males } & \multicolumn{3}{|c|}{ Females } \\
\hline & Control & 48-h PSD & 96-h PSD & Control & 48-h PSD & 96-h PSD \\
\hline \multicolumn{7}{|l|}{ Forced swim } \\
\hline Immobility(s) & $81 \pm 7$ & $\# 43 \pm 14$ & $\# 28 \pm 5$ & $82 \pm 9$ & ${ }^{*} 46 \pm 5$ & ${ }^{* \#} 85 \pm 16$ \\
\hline \multicolumn{7}{|l|}{ Open field } \\
\hline Rearing & $3 \pm 1$ & ${ }^{*} 1 \pm 1$ & $2 \pm 1$ & $3 \pm 1$ & $1 \pm 0.5$ & $2 \pm 0.8$ \\
\hline Grooming & $0.01 \pm 0.005$ & ${ }^{*} 2 \pm 0.43$ & ${ }^{*} 1 \pm 0.31$ & $0.01 \pm 0.005$ & $0.06 \pm 0.03$ & $0.43 \pm 0.31$ \\
\hline Locomotor activity $(\mathrm{cm})$ & $764 \pm 125$ & ${ }^{*} 296 \pm 118$ & *394 3166 & $764 \pm 125$ & $663 \pm 107$ & $513 \pm 101$ \\
\hline Time spend in the outer area & $0.493 \pm 0.3$ & $1.76 \pm 0.64$ & $1.41 \pm 0.55$ & $39.37 \pm 19$ & ${ }^{*} 165.6 \pm 18$ & ${ }^{*} 162.4 \pm 29$ \\
\hline \multicolumn{7}{|l|}{ Elevated Plus Maze } \\
\hline Open arms (s) & $92 \pm 11$ & $129 \pm 18$ & $109 \pm 15$ & $76 \pm 16$ & $* 44 \pm 13$ & ${ }^{*} 59 \pm 11$ \\
\hline Closed arms (s) & $162 \pm 13$ & $129 \pm 24$ & $130 \pm 17$ & $170 \pm 22$ & ${ }^{*} 225 \pm 15$ & $* 31 \pm 5$ \\
\hline Sucrose consumption $(\%)$ & $73 \pm 3$ & $58 \pm 10$ & $* 41 \pm 6$ & $73 \pm 4$ & $* 37 \pm 4$ & ${ }^{*} 57 \pm 4$ \\
\hline Corticosterone levels (ng/ml) & $60.50 \pm 7.3$ & $159 \pm 46$ & $75 \pm 37$ & $41 \pm 4$ & ${ }^{*} 245 \pm 63$ & ${ }^{*} 238 \pm 19$ \\
\hline
\end{tabular}

\#Statistically significant differences between males and females. *Statistically significant among the control vs experimental groups of the same sex.

stress associated with the PSD model [1]. This was one of the main reason to choice this method in our study. Our findings indicate that male mice showed a significant trend to depressive-like behaviors late after sleep deprivation. In contrast, female mice have a strong tendency to display anxiety- and depressive-like behaviors immediately after sleep deprivation as compared to males. To the best of our knowledge, this is the first report that establishes the behavioral differences in depressive- and anxiety-like behaviors between males and females after sleep-deprivation.

In both humans and animals, PSD is associated with the generation of anxiety- and depressive-type behaviors [39]. Recent evidence indicates that PSD can induce opposite effects on these behaviors [22]. Some studies report PSD-induced antidepressant effects [23, 47], whereas other studies reveal a depressive-like behavior after sleep deprivation [22]. Similar contradictory findings have been reported in anxiety-like behaviors induced by sleep deprivation [22]. Several experimental variables may explain these paradoxical data, such as: PSD period, observer bias, type of PSD model, animal strain, etc. [22, 47, 48].

Regarding the implication of the sex of individuals in behavioral assays, it has been found that males and females show differential performance in memory and learning tasks [22]. To the best of our knowledge, this is the first study that compares the effects of PSD in males vs. females. Our data confirmed that PSD induces anxiety- and depressive-like behaviors in all animals. Interestingly, PSD females appeared to be more susceptible to develop anxiety and short-term depressive be- havior than PSD males. In contrast, males showed a proclivity to develop long-lasting depressive-type behavior upon PSD. These findings suggest that sex hormones modify the vulnerability of the brain to sleep deprivation.

\section{Corticosterone levels between sexes}

Corticosterone blood level is considered a reliable indicator of anxiety onset and maintenance [18, 20,37]. In our study, corticosterone levels were higher in the 96-h PSD female group than in the 96-h PSD male group. Under physiological conditions, male mice show lower levels of glucocorticoids than females, which has been related to the regulation of estrogen receptors in the hypothalamic-pituitary axis [54]. Testosterone seems to act as neuroprotective against anxiogenic stimulus as compared to estrogen [22]. In consequence, male mice may habituate more efficiently to stressful stimuli [37].

A model of stress by sleep deprivation promotes corticosterone production [49]. In our study, we found that male mice showed a transient increase in corticosterone levels. However 96-h PSD male mice did not show this increment. Our data also indicate that female mice showed a persistent increase in the corticosterone levels after sleep deprivation. These findings support the notion that males may have more efficient mechanisms against stressors [22]. Female susceptibility may be attributed to their high estrogen levels that, in turn, can modify the expression of D2 receptors in the striatum [15], the cholinergic function [37] and the enzymatic activity of monoamine oxidase into the brain $[45,59]$. However, further studies involving corticosterone supplementation, 
castrations with sex hormone replacement or antidepressant treatment are needed to clarify the role of hypothalamic-pituitary axis and the balance of serotonin-dopamine in sleep-deprived individuals.

\section{Sleep deprivation promotes anxiety-type behavior}

In our study, we found that sleep-deprived females showed an increase in the time spent at the outer area of the field, which is indicative of anxiety-like behavior. Tucker et al. 2015, reported similar behavioral findings in brain injured female mice [50]. They observed that locomotor and cognitive performance of female animals varied according to the estrus cycle of mice, which indicates that female hormones are strong regulators of behavior. However, some authors suggest that locomotor performance in the open field is not affect by estrus cycle variations [56]. The time spent at the corners of the open field evaluates the natural tendency of animals to shelter themselves [7]. Herein, we report that PSDexposed females remain more time in the outer areas than males. Locomotion, evaluated in the open field test, is indicator motivation and anxiety [21, 42, 43]. Our data indicates that PSD promotes the locomotive activity in rodents, as reported previously $[54,55]$. In the elevated plus maze the time spent in the open arms is a reliable indicator of anxiety-like behavior [21], our findings indicated that sleep-deprived females show higher anxiety level as compared to males. Taken together, this evidence suggests the presence of sex-dependent behavioral differences in PSD animals. Nevertheless, since a 5-min observation was used in our study, we cannot discard that longer exposure to the open field may help display other behaviors in PSD animals.

Grooming activity is considered an adaptive behavior to stressful situations [24]. Our findings indicate that males showed more grooming than females. In rodents as in humans, estrogen hormones appear to promote anxiety and mood disorders [54]. This may be due to a positive feedback among the axis hypothalamus pituitary (HPA), $\mathrm{D}_{2}$ dopamine receptors and the monoamine system $[15,59]$. In fact, sleep deprivation activates dopaminergic neurons in the ventral tegmental area [28] and decreases the expression of dopamine receptors $\mathrm{D}_{2}$ and $\mathrm{D}_{3}$ in the ventral striatum, which have been associated with the control of the awakening [53]. Knockout mice that lack GRs show important sex-dependent differences in development and hyperactivity of depressivetype behaviors [14]. This suggests that alterations in the
HPA are associated with the development of depressivetype behavior in a sex-dependent manner. Yet, the role of sex hormones in PSD-induced anxiety remains to be elucidated.

PSD produces a long-term effect in depressive-like behaviors

A decrease in the activity period in the forced swim test is an indicator of depressive-type behavior [46]. In this study, we utilized this test to assess the depressive behavior immediately after sleep deprivation. Our findings indicate that PSD reduces the depression-type behavior when assessed immediately after PSD. In fact, male mice appeared to be more resilient to display depressive-type behavior as compared to females, but the biological meaning of these behavioral changes are not known. An alternative explanation for the changes observed in the forced swim test may be due to an increase in the locomotive activity induced by PSD [54, 55]. Similar behavioral changes have been related to regional changes in neurotransmitter levels [30]. The sucrose consumption test is a method to evaluate anhedonia (another depressive-type behavior) in rodents [46]. In our study, we used this test to investigate the long-lasting depressive-like behavior. We found that sleep-deprived males consumed less sucrose compared with females. Taken together, our findings suggest that males have a proclivity to show long-lasting depression, but are resilient to develop depressive behaviors immediately after sleep deprivation. However, a full set of depression assays are required to completely determine whether the sex define depression-like behaviors.

PSD generates sex-dependent effects in anxiety and depressive-type behaviors. In particular, sleep deprivation promotes anxiety-type behavior in females. Female mice also show evident depressive-like behavior immediately after sleep deprivation. In contrast, male mice appear to have proclivity to develop a persistent depressive-like behavior upon sleep deprivation. In summary, sleep deprivation produces sex-dependent effects in anxiety and depression.

\section{Acknowledgments}

This work was supported by COECYTJAL's grant PS-2009-827 (R.E.G-C) and PROMEP's grant "Redes 2014" (OGP) and Redes Tematicas (OGP) CONACyT No. 251132. 


\section{References}

1. Allard, J.S., Tizabi, Y., Shaffery, J.P., and Manaye, K. 2007. Effects of rapid eye movement sleep deprivation on hypocretin neurons in the hypothalamus of a rat model of depression. Neuropeptides 41: 329-337. [Medline] [CrossRef]

2. Banks, S. and Dinges, D.F. 2007. Behavioral and physiological consequences of sleep restriction. J. Clin. Sleep Med. 3: 519-528. [Medline]

3. Bridoux, A., Laloux, C., Derambure, P., Bordet, R., and Monaca Charley, C. 2013. The acute inhibition of rapid eye movement sleep by citalopram may impair spatial learning and passive avoidance in mice. J. Neural Transm. 120:383389. [Medline] [CrossRef]

4. Brown, R.E., Basheer, R., McKenna, J.T., Strecker, R.E., and McCarley, R.W. 2012. Control of sleep and wakefulness. Physiol. Rev. 92: 1087-1187. [Medline] [CrossRef]

5. Campbell, I.G., Darchia, N., Khaw, W.Y., Higgins, L.M., and Feinberg, I. 2005. Sleep EEG evidence of sex differences in adolescent brain maturation. Sleep 28: 637-643. [Medline]

6. Cao, D., Lu, H., Lewis, T.L., and Li, L. 2007. Intake of sucrose-sweetened water induces insulin resistance and exacerbates memory deficits and amyloidosis in a transgenic mouse model of Alzheimer disease. J. Biol. Chem. 282: 36275-36282. [Medline] [CrossRef]

7. Carola, V., D’Olimpio, F., Brunamonti, E., Mangia, F., and Renzi, P. 2002. Evaluation of the elevated plus-maze and open-field tests for the assessment of anxiety-related behaviour in inbred mice. Behav. Brain Res. 134: 49-57. [Medline] [CrossRef]

8. Castagne, V., Moser, P., Roux, S., and Porsolt, R.D.2011. Rodent models of depression: forced swim and tail suspension behavioral despair tests in rats and mice. Curr Protoc Neurosci. Chapter 8: p. Unit 8 10A.

9. Castagné, V., Porsolt, R.D., and Moser, P. 2009. Use of latency to immobility improves detection of antidepressant-like activity in the behavioral despair test in the mouse. Eur. $J$. Pharmacol. 616: 128-133. [Medline] [CrossRef]

10. Clemett, D.A., Cockett, M.I., Marsden, C.A., and Fone, K.C. 1998. Antisense oligonucleotide-induced reduction in 5-hydroxytryptamine7 receptors in the rat hypothalamus without alteration in exploratory behaviour or neuroendocrine function. J. Neurochem. 71: 1271-1279. [Medline] [CrossRef]

11. Coenen, A.M. and Van Hulzen, Z.J. 1980. Paradoxical sleep deprivation in animal studies: some methodological considerations. Prog. Brain Res. 53: 325-330. [Medline] [CrossRef]

12. Crawley, J.N., Belknap, J.K., Collins, A., Crabbe, J.C., Frankel, W., Henderson, N., Hitzemann, R.J., Maxson, S.C., Miner, L.L., Silva, A.J., Wehner, J.M., Wynshaw-Boris, A., and Paylor, R. 1997. Behavioral phenotypes of inbred mouse strains: implications and recommendations for molecular studies. Psychopharmacology (Berl.) 132: 107-124. [Medline] [CrossRef]

13. Dijk, D.J., Beersma, D.G., and Bloem, G.M. 1989. Sex differences in the sleep EEG of young adults: visual scoring and spectral analysis. Sleep 12: 500-507. [Medline]

14. Espallergues, J., Teegarden, S.L., Veerakumar, A., Boulden,
J., Challis, C., Jochems, J., Chan, M., Petersen, T., Deneris, E., Matthias, P., Hahn, C.G., Lucki, I., Beck, S.G., and Berton, O. 2012. HDAC6 regulates glucocorticoid receptor signaling in serotonin pathways with critical impact on stress resilience. J. Neurosci. 32: 4400-4416. [Medline] [CrossRef]

15. Fink, G., Sumner, B.E., Rosie, R., Grace, O., and Quinn, J.P. 1996. Estrogen control of central neurotransmission: effect on mood, mental state, and memory. Cell. Mol. Neurobiol. 16: 325-344. [Medline] [CrossRef]

16. Goel, N., Basner, M., Rao, H., and Dinges, D.F. 2013. Circadian rhythms, sleep deprivation, and human performance. Prog. Mol. Biol. Transl. Sci. 119: 155-190. [Medline] [CrossRef]

17. Goerke, M., Cohrs, S., Rodenbeck, A., Grittner, U., Sommer, W., and Kunz, D. 2013. Declarative memory consolidation during the first night in a sleep lab: the role of REM sleep and cortisol. Psychoneuroendocrinology 38: 1102-1111. [Medline] [CrossRef]

18. Gonzalez-Perez, O., Chavez-Casillas, O., Jauregui-Huerta, F., Lopez-Virgen, V., Guzman-Muniz, J., Moy-Lopez, N., Gonzalez-Castaneda, R.E., and Luquin, S. 2011. Stress by noise produces differential effects on the proliferation rate of radial astrocytes and survival of neuroblasts in the adult subgranular zone. Neurosci. Res. 70: 243-250. [Medline] [CrossRef]

19. Gonzalez-Perez, O., Gutierrez-Fernandez, F., Lopez-Virgen, V., Collas-Aguilar, J., Quinones-Hinojosa, A., and GarciaVerdugo, J.M. 2012. Immunological regulation of neurogenic niches in the adult brain. Neuroscience 226: 270-281. [Medline] [CrossRef]

20. Gonzalez-Perez, O., Jauregui-Huerta, F., and Galvez-Contreras, A.Y. 2010. Immune system modulates the function of adult neural stem cells. Curr. Immunol. Rev. 6: 167-173. [Medline] [CrossRef]

21. Gonzalez-Perez, O., Ramos-Remus, C., Garcia-Estrada, J., and Luquin, S. 2001. Prednisone induces anxiety and glial cerebral changes in rats. J. Rheumatol. 28: 2529-2534. [Medline]

22. Hajali, V., Sheibani, V., Esmaeili-Mahani, S., and Shabani, M. 2012. Female rats are more susceptible to the deleterious effects of paradoxical sleep deprivation on cognitive performance. Behav. Brain Res. 228: 311-318. [Medline] [CrossRef]

23. Howland, R.H. 2011. Sleep interventions for the treatment of depression. J. Psychosoc. Nurs. Ment. Health Serv. 49: 17-20. [Medline]

24. Kalueff, A.V. and Tuohimaa, P. 2005. The grooming analysis algorithm discriminates between different levels of anxiety in rats: potential utility for neurobehavioural stress research. J. Neurosci. Methods 143: 169-177. [Medline] [CrossRef]

25. Kasai, T., Floras, J.S., and Bradley, T.D. 2012. Sleep apnea and cardiovascular disease: a bidirectional relationship. Circulation 126: 1495-1510. [Medline] [CrossRef]

26. Klejbor, I., Ludkiewicz, B., and Turlejski, K. 2013. Effect of light-dark changes on the locomotor activity in open field in adult rats and opossums. Folia Morphol. (Warsz) 72: 300305. [Medline] [CrossRef] 
27. Kobayashi, I., Cowdin, N., and Mellman, T.A. 2012. One's sex, sleep, and posttraumatic stress disorder. Biol. Sex Differ. 3: 29. [Medline] [CrossRef]

28. Lima, M.M., Andersen, M.L., Reksidler, A.B., Ferraz, A.C., Vital, M.A., and Tufik, S. 2012. Paradoxical sleep deprivation modulates tyrosine hydroxylase expression in the nigrostriatal pathway and attenuates motor deficits induced by dopaminergic depletion. CNS Neurol. Disord. Drug Targets 11: 359-368. [Medline] [CrossRef]

29. Linge, R., Pazos, Á., and Díaz, Á. 2013. Social isolation differentially affects anxiety and depressive-like responses of bulbectomized mice. Behav. Brain Res. 245: 1-6. [Medline] [CrossRef]

30. Lopez-Rodriguez, F., Kim, J., and Poland, R.E. 2004. Total sleep deprivation decreases immobility in the forced-swim test. Neuropsychopharmacology 29: 1105-1111. [Medline] [CrossRef]

31. Machado, R.B., Hipólide, D.C., Benedito-Silva, A.A., and Tufik, S. 2004. Sleep deprivation induced by the modified multiple platform technique: quantification of sleep loss and recovery. Brain Res. 1004: 45-51. [Medline] [CrossRef]

32. Machado, R.B., Suchecki, D., and Tufik, S. 2006. Comparison of the sleep pattern throughout a protocol of chronic sleep restriction induced by two methods of paradoxical sleep deprivation. Brain Res. Bull. 70: 213-220. [Medline] [CrossRef]

33. Mansukhani, M.P., Kolla, B.P., Surani, S., Varon, J., and Ramar, K. 2012. Sleep deprivation in resident physicians, work hour limitations, and related outcomes: a systematic review of the literature. Postgrad. Med. 124: 241-249. [Medline] [CrossRef]

34. Mednick, S.C., McDevitt, E.A., Walsh, J.K., Wamsley, E., Paulus, M., Kanady, J.C., and Drummond, S.P. 2013. The critical role of sleep spindles in hippocampal-dependent memory: a pharmacology study. J. Neurosci. 33: 4494-4504. [Medline] [CrossRef]

35. Mous, S.E., Muetzel, R.L., El Marroun, H., Polderman, T.J., van der Lugt, A., Jaddoe, V.W., Hofman, A., Verhulst, F.C., Tiemeier, H., Posthuma, D., and White, T. 2014. Cortical thickness and inattention/hyperactivity symptoms in young children: a population-based study. Psychol. Med. 44: 32033213. [Medline] [CrossRef]

36. Neafsey, D.E., Waterhouse, R.M., Abai, M.R., Aganezov, S.S., Alekseyev, M.A., Allen, J.E., Amon, J., Arcà, B., Arensburger, P., Artemov, G., Assour, L.A., Basseri, H., Berlin, A., Birren, B.W., Blandin, S.A., Brockman, A.I., Burkot, T.R., Burt, A., Chan, C.S., Chauve, C., Chiu, J.C., Christensen, M., Costantini, C., Davidson, V.L., Deligianni, E., Dottorini, T., Dritsou, V., Gabriel, S.B., Guelbeogo, W.M., Hall, A.B., Han, M.V., Hlaing, T., Hughes, D.S., Jenkins, A.M., Jiang, X., Jungreis, I., Kakani, E.G., Kamali, M., Kemppainen, P., Kennedy, R.C., Kirmitzoglou, I.K., Koekemoer, L.L., Laban, N., Langridge, N., Lawniczak, M.K., Lirakis, M., Lobo, N.F., Lowy, E., MacCallum, R.M., Mao, C., Maslen, G., Mbogo, C., McCarthy, J., Michel, K., Mitchell, S.N., Moore, W., Murphy, K.A., Naumenko, A.N., Nolan, T., Novoa, E.M., O’Loughlin, S., Oringanje, C., Oshaghi, M.A., Pakpour, N., Papathanos, P.A., Peery, A.N., Povelones, M.,
Prakash, A., Price, D.P., Rajaraman, A., Reimer, L.J., Rinker, D.C., Rokas, A., Russell, T.L., Sagnon, N., Sharakhova, M.V., Shea, T., Simão, F.A., Simard, F., Slotman, M.A., Somboon, P., Stegniy, V., Struchiner, C.J., Thomas, G.W., Tojo, M., Topalis, P., Tubio, J.M., Unger, M.F., Vontas, J., Walton, C., Wilding, C.S., Willis, J.H., Wu, Y.C., Yan, G., Zdobnov, E.M., Zhou, X., Catteruccia, F., Christophides, G.K., Collins, F.H., Cornman, R.S., Crisanti, A., Donnelly, M.J., Emrich, S.J., Fontaine, M.C., Gelbart, W., Hahn, M.W., Hansen, I.A., Howell, P.I., Kafatos, F.C., Kellis, M., Lawson, D., Louis, C., Luckhart, S., Muskavitch, M.A., Ribeiro, J.M., Riehle, M.A., Sharakhov, I.V., Tu, Z., Zwiebel, L.J., and Besansky, N.J. 2015. Mosquito genomics. Highly evolvable malaria vectors: the genomes of 16 Anopheles mosquitoes. Science 347: 1258522. [Medline] [CrossRef]

37. Palanza, P. 2001. Animal models of anxiety and depression: how are females different? Neurosci. Biobehav. Rev. 25: 219-233. [Medline] [CrossRef]

38. Paul, K.N., Turek, F.W., and Kryger, M.H. 2008. Influence of sex on sleep regulatory mechanisms. J. Womens Health (Larchmt) 17: 1201-1208. [Medline] [CrossRef]

39. Phillips, B.A., Collop, N.A., Drake, C., Consens, F., Vgontzas, A.N., and Weaver, T.E. 2008. Sleep disorders and medical conditions in women. Proceedings of the Women \& Sleep Workshop, National Sleep Foundation, Washington, DC, March 5-6, 2007. J. Womens Health (Larchmt) 17: 1191-1199. [Medline] [CrossRef]

40. Pohl, J., Olmstead, M.C., Wynne-Edwards, K.E., Harkness, K., and Menard, J.L. 2007. Repeated exposure to stress across the childhood-adolescent period alters rats' anxietyand depression-like behaviors in adulthood: The importance of stressor type and gender. Behav. Neurosci. 121: 462-474. [Medline] [CrossRef]

41. Porsolt, R.D. 1979. Animal model of depression. Biomedicine 30: 139-140. [Medline]

42. Rodgers, R.J. 1997. Animal models of 'anxiety': where next? Behav. Pharmacol. 8: 477-496, discussion 497-504. [Medline] [CrossRef]

43. Rodgers, R.J., Cao, B.J., Dalvi, A., and Holmes, A. 1997. Animal models of anxiety: an ethological perspective. Braz. J. Med. Biol. Res. 30: 289-304. [Medline] [CrossRef]

44. Rohleder, N., Aringer, M., and Boentert, M. 2012. Role of interleukin-6 in stress, sleep, and fatigue. Ann. N. Y. Acad. Sci. 1261: 88-96. [Medline] [CrossRef]

45. Safa, M., Sadr, S., Talischi, F., and Ghasem Boroujerdi, F. 2013. Study of effects of selective serotonin reuptake inhibitors on stages of sexual function in Iranian patients with major depressive disorder. Ther. Adv. Psychopharmacol. 3: 306-313. [Medline] [CrossRef]

46. Solomon, M.B., Furay, A.R., Jones, K., Packard, A.E., Packard, B.A., Wulsin, A.C., and Herman, J.P. 2012. Deletion of forebrain glucocorticoid receptors impairs neuroendocrine stress responses and induces depression-like behavior in males but not females. Neuroscience 203: 135-143. [Medline] [CrossRef]

47. Suchecki, D., Tiba, P.A., and Machado, R.B. 2012. REM Sleep Rebound as an Adaptive Response to Stressful Situations. Front Neurol. 3: 41. [Medline] [CrossRef] 
48. Tartar, J.L., Ward, C.P., Cordeira, J.W., Legare, S.L., Blanchette, A.J., McCarley, R.W., and Strecker, R.E. 2009. Experimental sleep fragmentation and sleep deprivation in rats increases exploration in an open field test of anxiety while increasing plasma corticosterone levels. Behav. Brain Res. 197: 450-453. [Medline] [CrossRef]

49. Thamaraiselvi, K., Mathangi, D.C., and Subhashini, A.S. 2012. REM sleep deprivation: A stressor. Int. J. Biol. Med. Res. 3: 2390-2394.

50. Tucker, L.B., Fu, A.H., and McCabe, J.T. 2015. Performance of male and female $\mathrm{C} 57 \mathrm{BL} / 6 \mathrm{~J}$ mice on motor and cognitive tasks commonly used in pre-clinical traumatic brain injury research. J. Neurotrauma. (in press). [Medline] [CrossRef]

51. Van Hulzen, Z.J. and Coenen, A.M. 1980. The pendulum technique for paradoxical sleep deprivation in rats. Physiol. Behav. 25: 807-811. [Medline] [CrossRef]

52. Vitulano, N., Di Marco Berardino, A., Re, A., Riccioni, G., Perna, F., Mormile, F., Valente, S., and Bellocci, F. 2013. Obstructive sleep apnea and heart disease: the biomarkers point of view. Front. Biosci. (Schol. Ed.) 5: 588-599. [Medline] [CrossRef]

53. Volkow, N.D., Tomasi, D., Wang, G.J., Telang, F., Fowler, J.S., Logan, J., Benveniste, H., Kim, R., Thanos, P.K., and Ferré, S. 2012. Evidence that sleep deprivation downregulates dopamine D2R in ventral striatum in the human brain. J. Neurosci. 32: 6711-6717. [Medline] [CrossRef]
54. Walf, A.A. and Frye, C.A. 2006. A review and update of mechanisms of estrogen in the hippocampus and amygdala for anxiety and depression behavior. Neuropsychopharmacology 31: 1097-1111. [Medline]

55. Walf, A.A. and Frye, C.A. 2007. Administration of estrogen receptor beta-specific selective estrogen receptor modulators to the hippocampus decrease anxiety and depressive behavior of ovariectomized rats. Pharmacol. Biochem. Behav. 86: 407-414. [Medline] [CrossRef]

56. Walf, A.A., Koonce, C., Manley, K., and Frye, C.A. 2009. Proestrous compared to diestrous wildtype, but not estrogen receptor beta knockout, mice have better performance in the spontaneous alternation and object recognition tasks and reduced anxiety-like behavior in the elevated plus and mirror maze. Behav. Brain Res. 196: 254-260. [Medline] [CrossRef]

57. Wells, M.E. and Vaughn, B.V. 2012. Poor sleep challenging the health of a Nation. Neurodiagn. J. 52: 233-249. [Medline]

58. Yang, S.R., Sun, H., Huang, Z.L., Yao, M.H., and Qu, W.M. 2012. Repeated sleep restriction in adolescent rats altered sleep patterns and impaired spatial learning/memory ability. Sleep 35: 849-859. [Medline] [CrossRef]

59. Yonkers, K.A. and White, K. 1992. Premenstrual exacerbation of depression: one process or two? J. Clin. Psychiatry 53: 289-292. [Medline] 